\title{
Internal Morphology-Controllable Self-Assembly in Poly(Ionic Liquid) Nanoparticles
}

Weiyi Zhang, ${ }^{\dagger}$ Zdravko Kochovski, ${ }^{\ddagger}$ Yan Lu, ${ }^{\ddagger}$ Bernhard V.K.J. Schmidt, ${ }^{\dagger}{ }^{\dagger}$ Markus

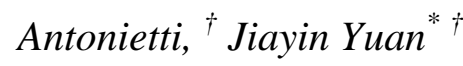

${ }^{\dagger}$ Max-Planck-Institute of Colloids and Interfaces, D-14476 Potsdam, Germany

‡ Soft Matter and Functional Materials, Helmholtz-Zentrum Berlin für Materialien und Energie, Hahn-Meitner-Platz 1, 14109 Berlin, Germany .

KEYWORDS: poly(ionic liquid) nanoparticles • self-assembly • shape controllable $\bullet$ fine interior structure • cryo-EM, ET measurement 


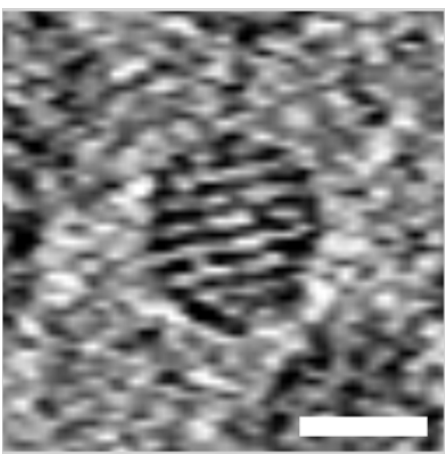

Movie 1 (file C12_tomo.avi). Poly(TILM-C12Br) nanoparticle. Related to Fig. 3 (A, B and C). Cryo-ET of a single poly(TILMC12Br) nanoparticle.

Initially, tomographic slices along the $\mathrm{Z}$ axis of the tomographic volume are shown. Then, a rendering of the entire segmented particle appears. In what follows, the particle is being gradually clipped along the $\mathrm{Z}$ axis, with the clipping plane reaching its central region. Finally the whole volume is being rotated back and forth along the $\mathrm{X}$ axis for a better visualization of the particle internal structure. (scale bar: $25 \mathrm{~nm})$

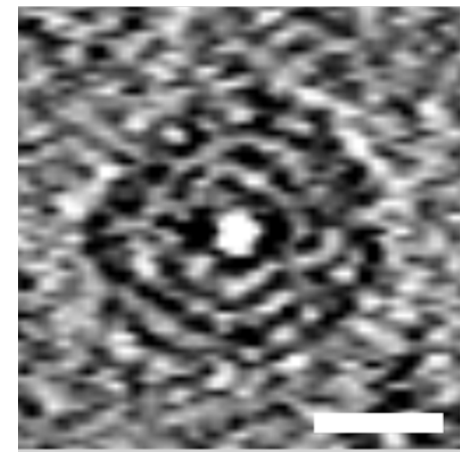

Movie 2 (file C16_tomo.avi). Poly(TILM-C16Br) nanoparticle. Related to Fig. 3 (D, E and F). Cryo-ET of a single poly(TILMC16Br) nanoparticle.

Initially, tomographic slices along the $\mathrm{Z}$ axis of the tomographic volume are shown. Then, a rendering of the entire segmented particle appears. In what follows, the particle is being gradually clipped along the $\mathrm{Z}$ axis, with the clipping plane reaching its central region. Finally the whole volume is being rotated back and forth along the $\mathrm{X}$ axis for a better visualization of the particle internal structure. (scale bar: $25 \mathrm{~nm})$ 
Triazolium ionic liquid monomers

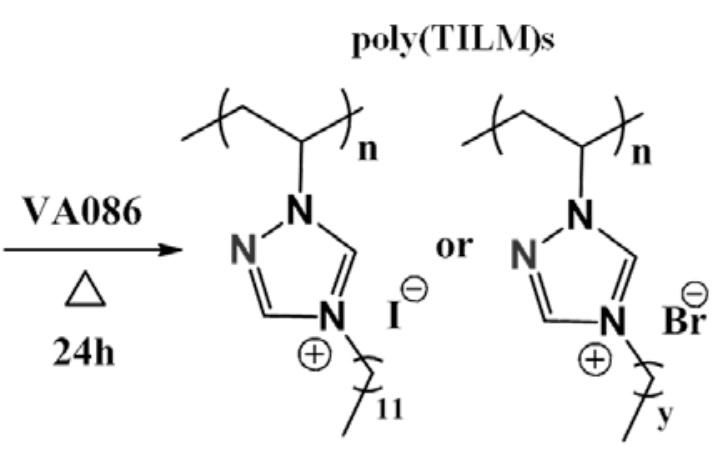

$$
\begin{aligned}
& \mathrm{RX}=\mathrm{C}_{12} \mathrm{H}_{25}-\mathrm{I} \quad \mathrm{y}=11,13 \text { and } 15 \\
& \mathrm{C}_{12} \mathrm{H}_{25}-\mathrm{Br} \\
& \mathrm{C}_{14} \mathrm{H}_{29}-\mathrm{Br} \\
& \mathrm{C}_{16} \mathrm{H}_{33}-\mathrm{Br}
\end{aligned}
$$

VA086:

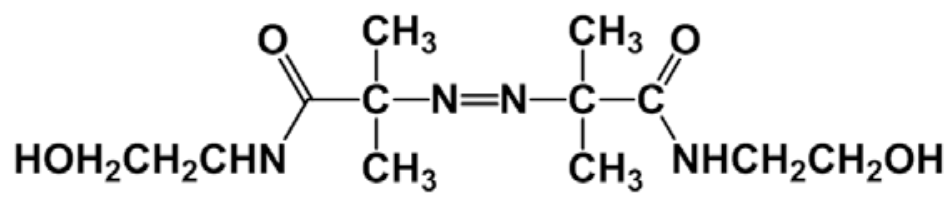

Figure S1. Synthetic route toward triazolium-based poly(ionic liquid) (TPIL) nanoparticles. VA86 serves as water-soluble thermoinitiator. 

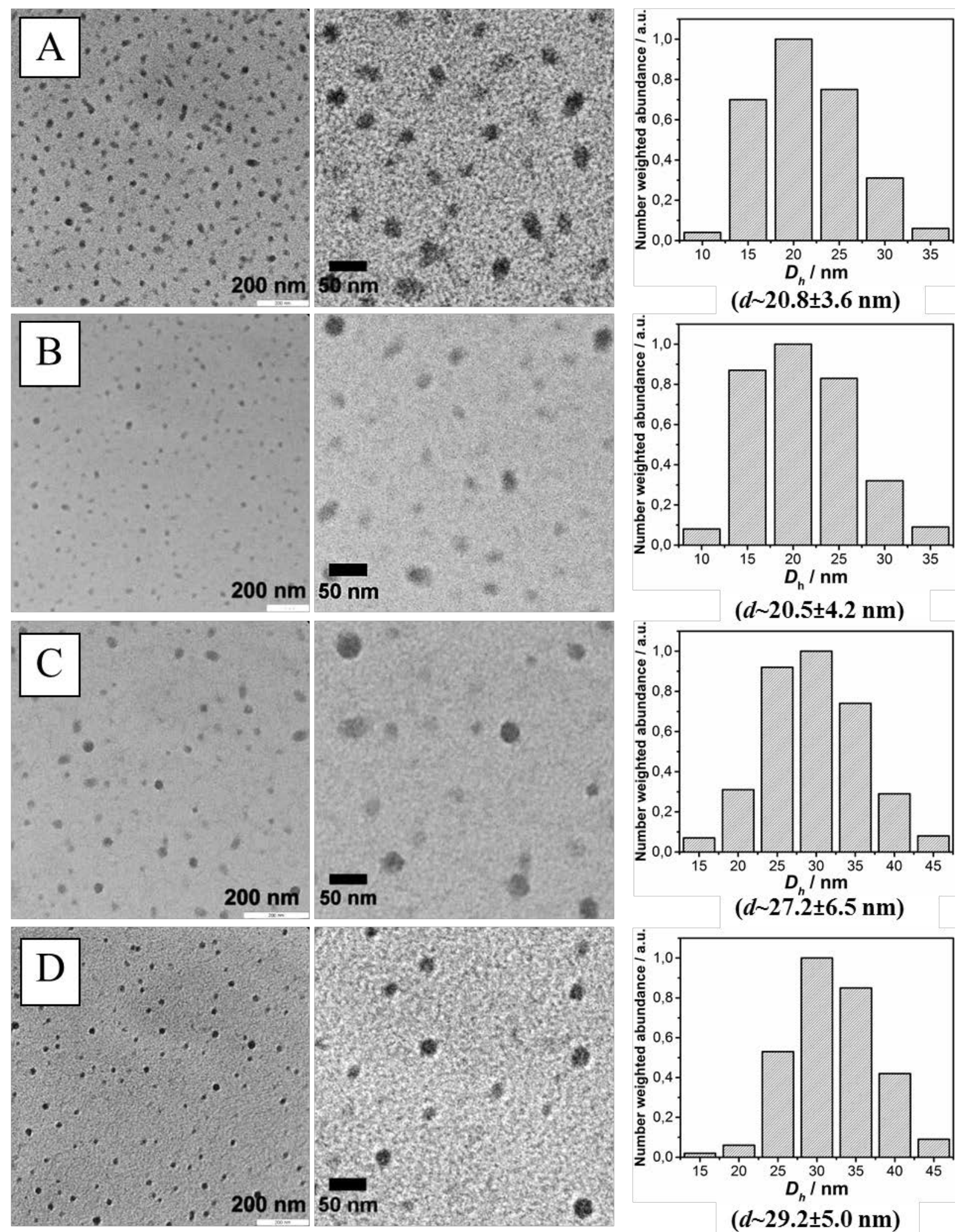

Figure S2. TEM images and number-averaged particle size distributions obtained via DLS of poly(ionic liquid) nanoparticles prepared from poly(TILM-C12I) (A), poly(TILM-C12Br) (B); poly(TILM-C14Br) (C); and poly(TILM-C16Br) polymers. All samples are measured in a concentration of $0.4 \mathrm{~g} / \mathrm{L}$ in water. 

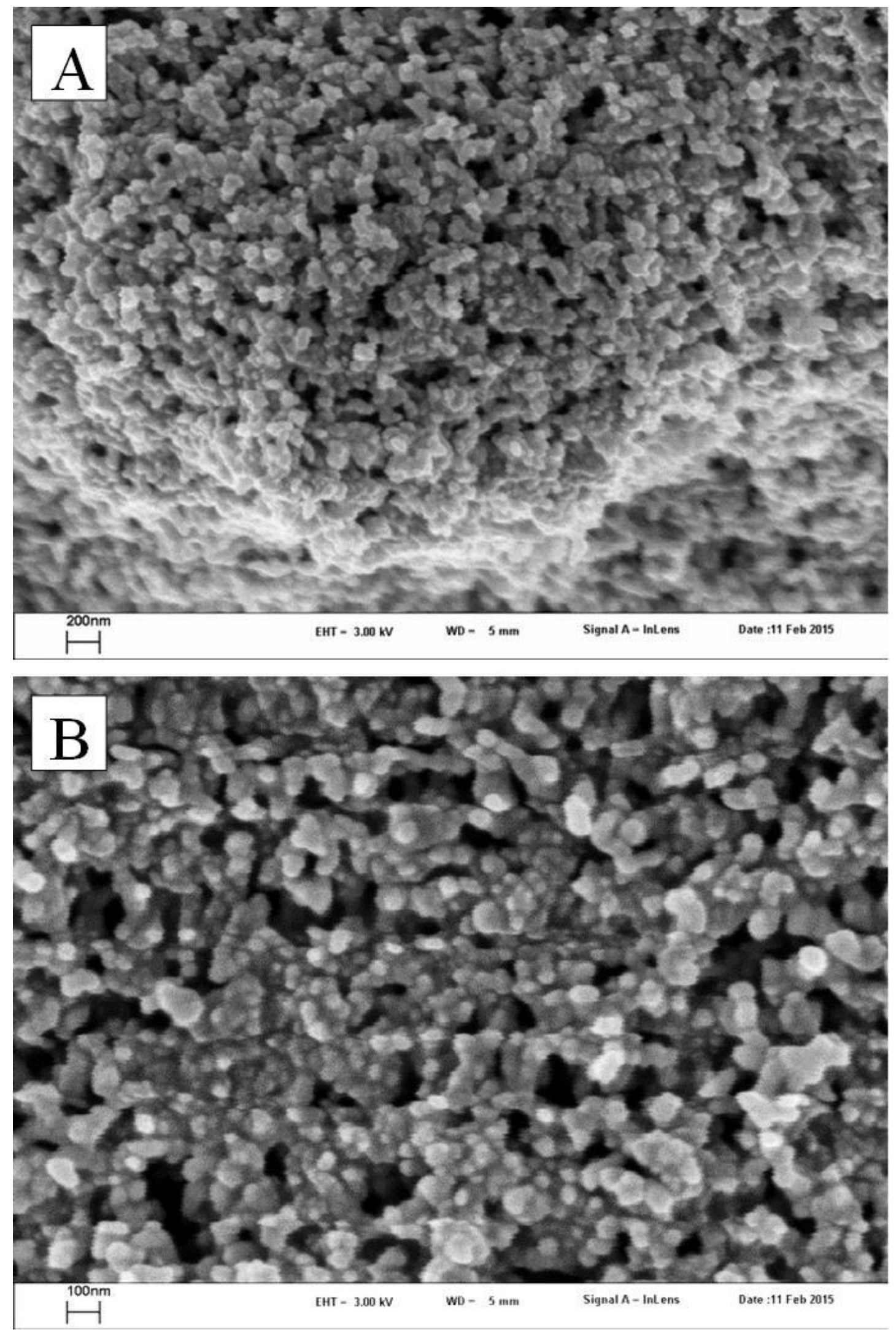
Figure S3. SEM images of poly(TILM-C12Br) nanoparticles prepared via drop casting of its aqueous dispersion. (A) overview; (B) close view.

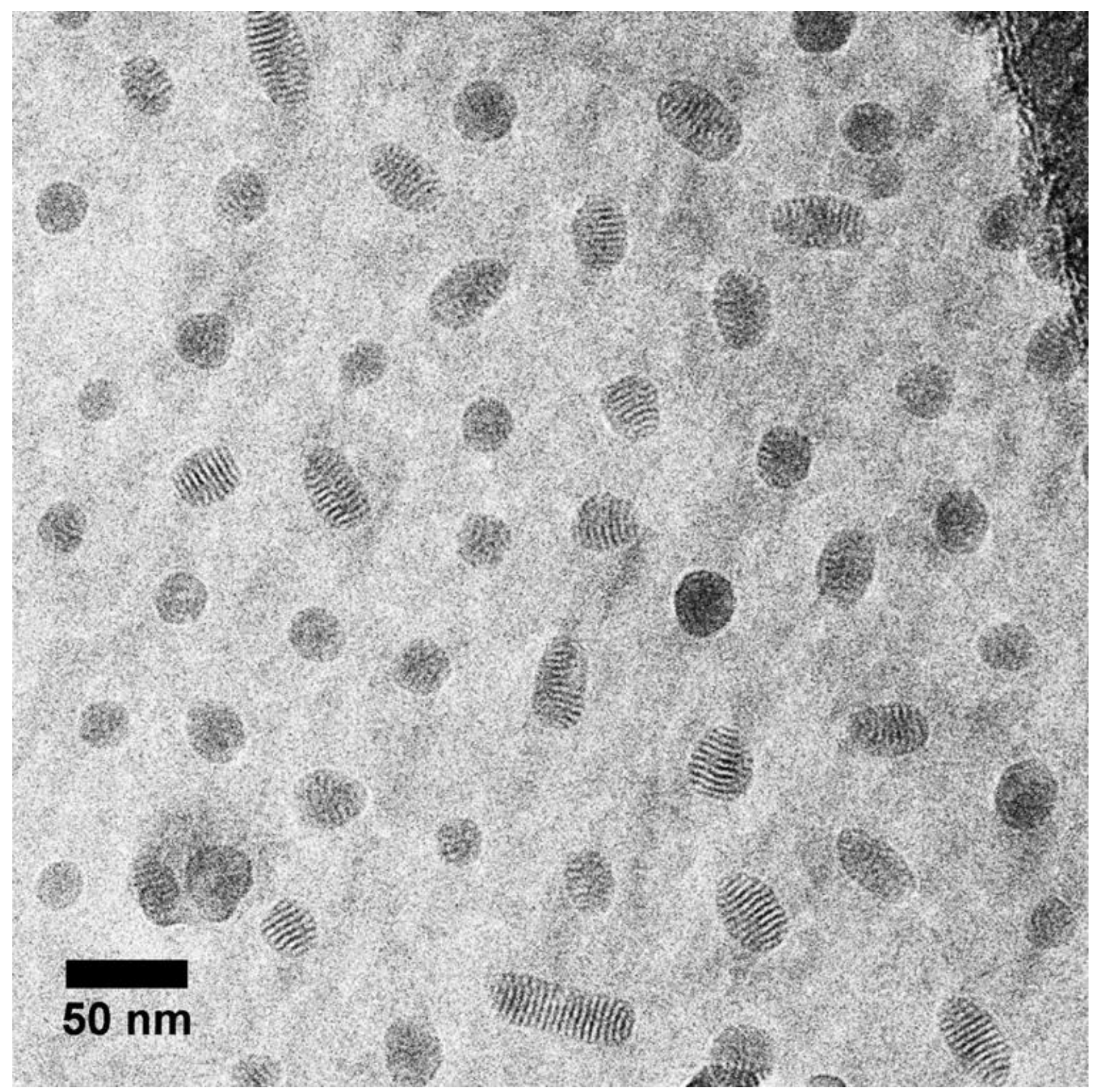

Figure S4. Overview of a cryo-EM image of poly(TILM-C12I) PIL nanoparticles in aqueous dispersion. 


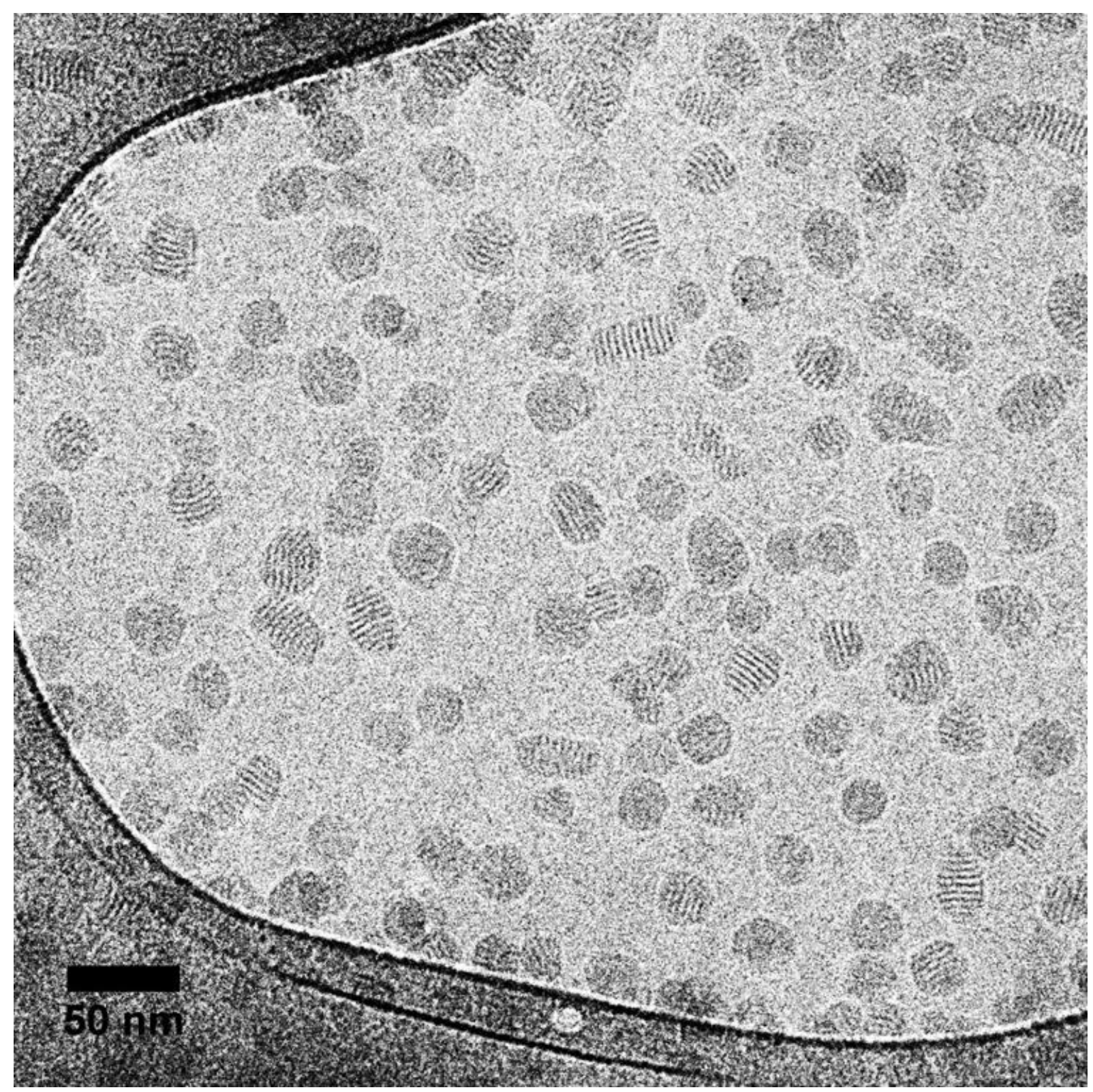

Figure S5. Overview of a cryo-EM image of poly(TILM-C12Br) PIL nanoparticles in aqueous dispersion. 


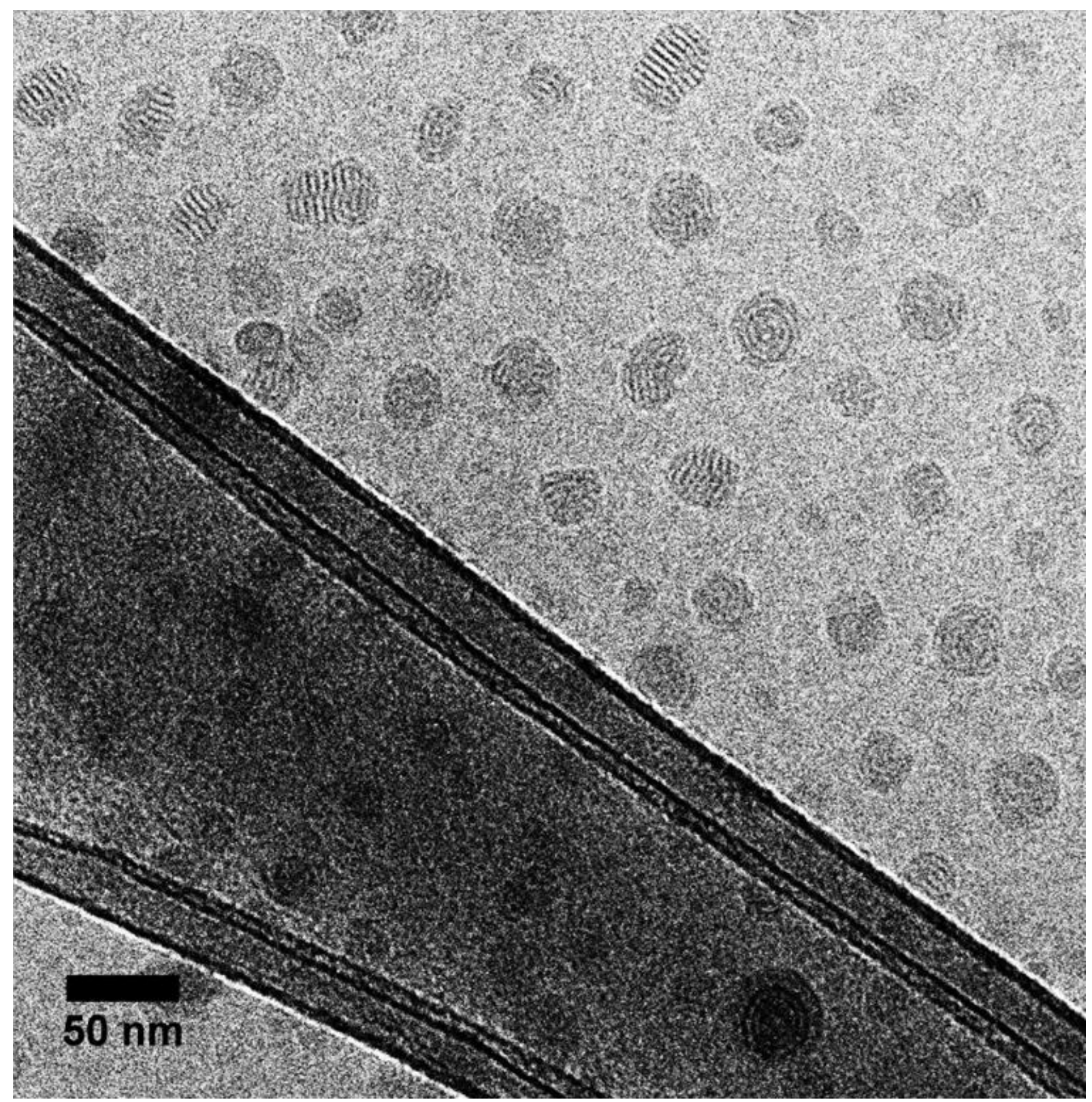

Figure S6. Overview of a cryo-EM image of poly(TILM-C14Br) PIL nanoparticles in aqueous dispersion. 


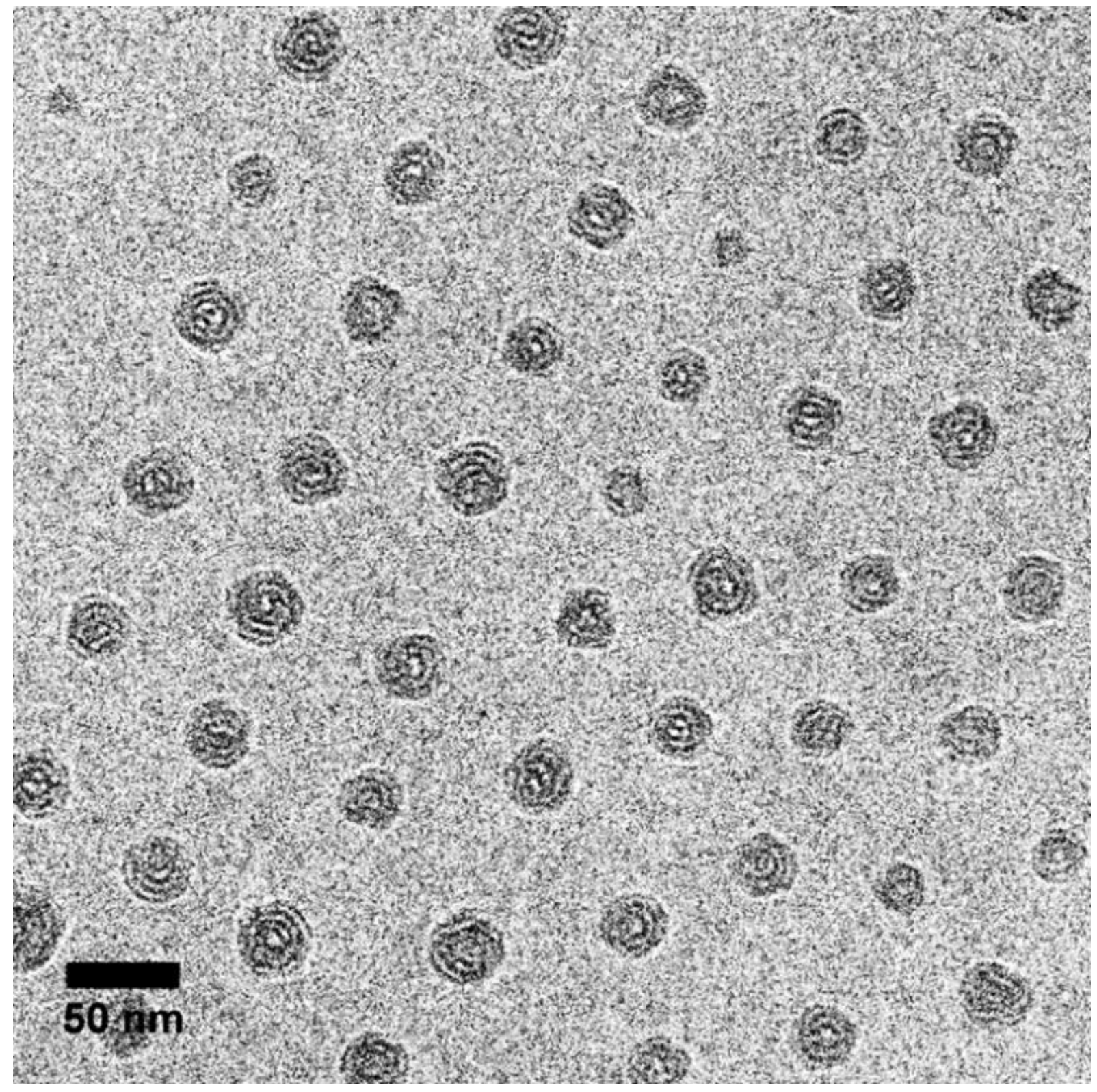

Figure S7. Overview of a cryo-EM image of poly(TILM-C16Br) PIL nanoparticles in aqueous dispersion. 


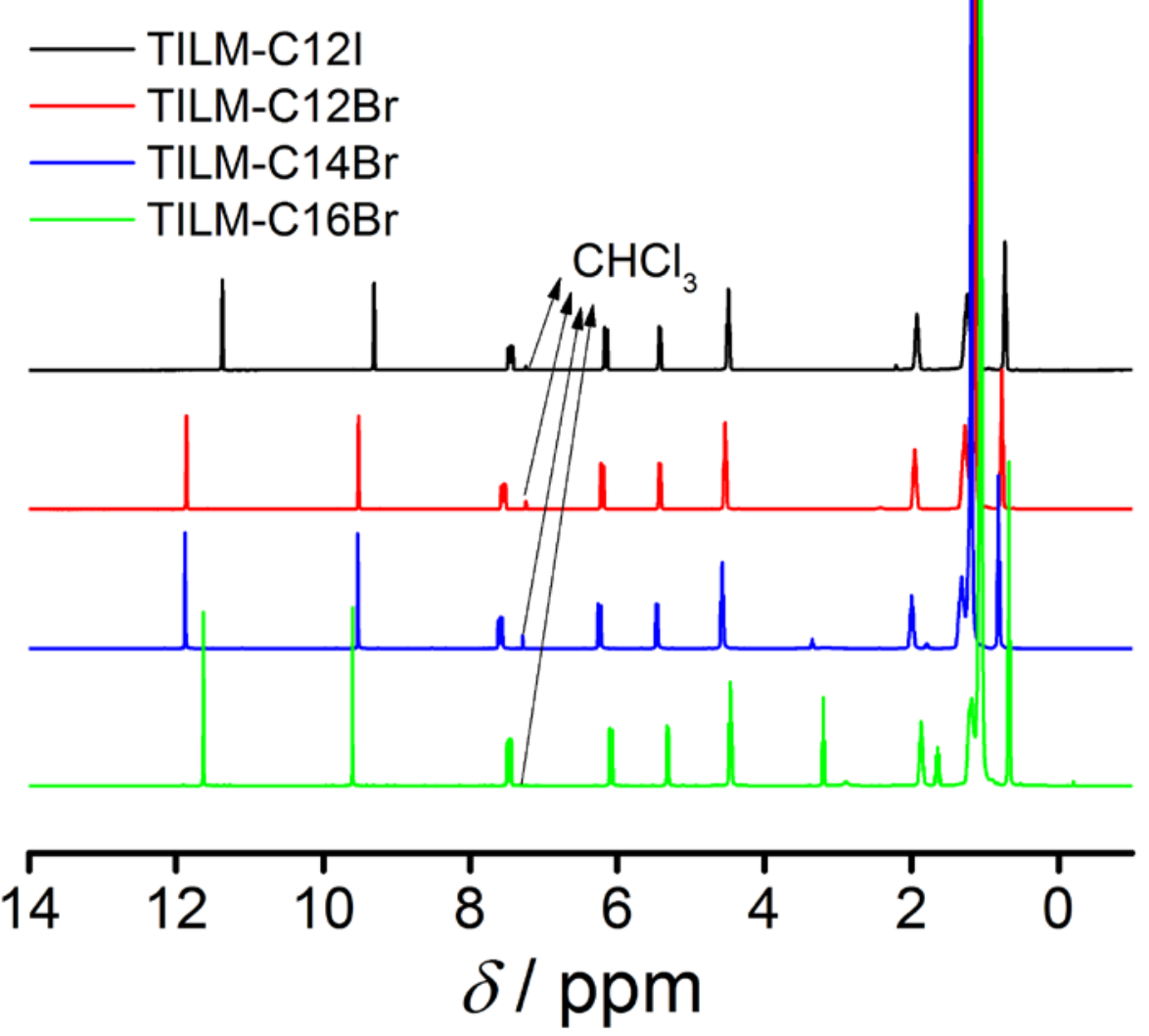

Figure S8. ${ }^{1} \mathrm{H}-\mathrm{NMR}$ spectra of the triazolium ionic liquid monomers in $\mathrm{CDCl}_{3}$.

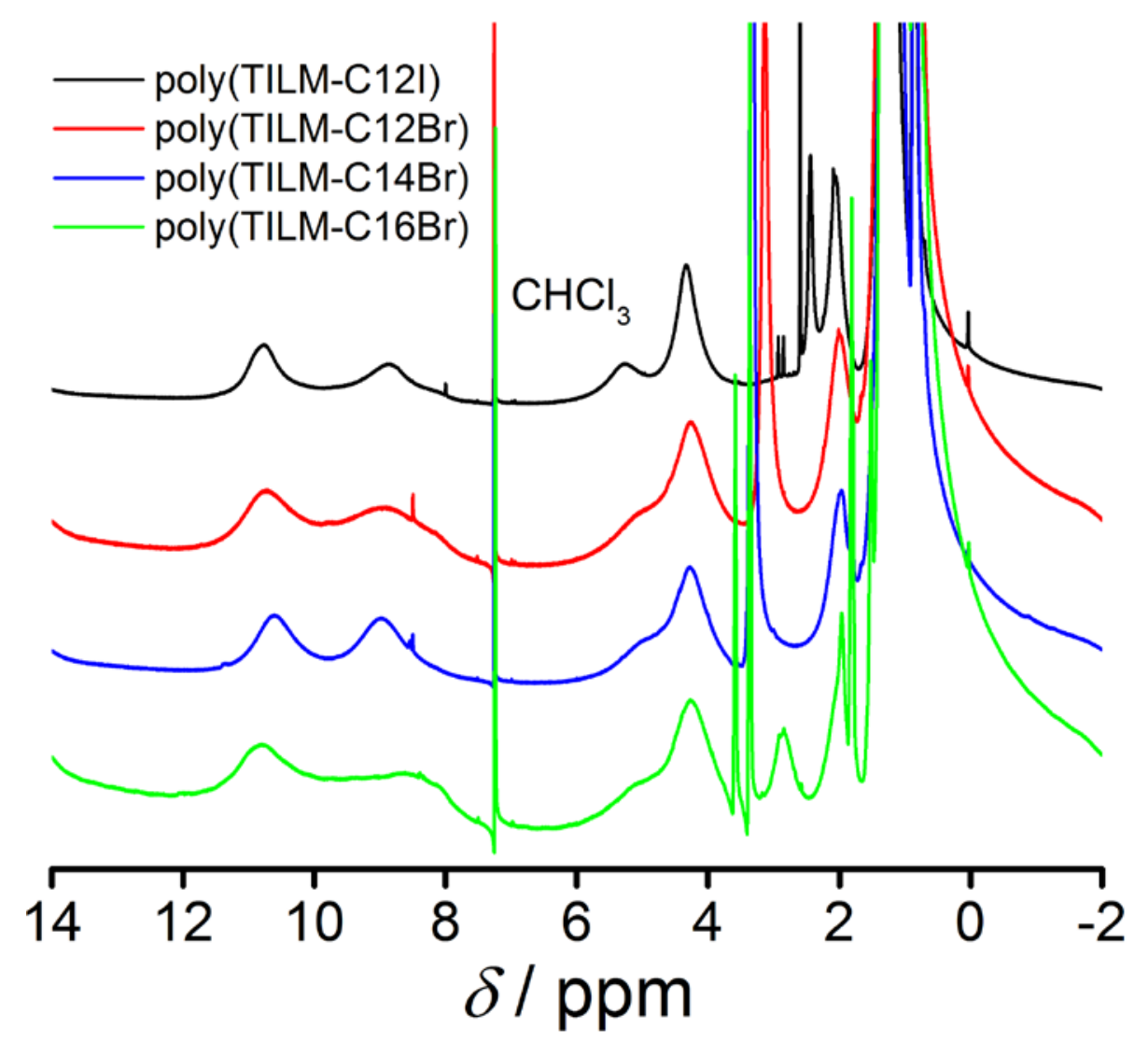

Figure S9. ${ }^{1} \mathrm{H}-\mathrm{NMR}$ spectra of poly(ionic liquid)s in $\mathrm{CDCl}_{3}$. 


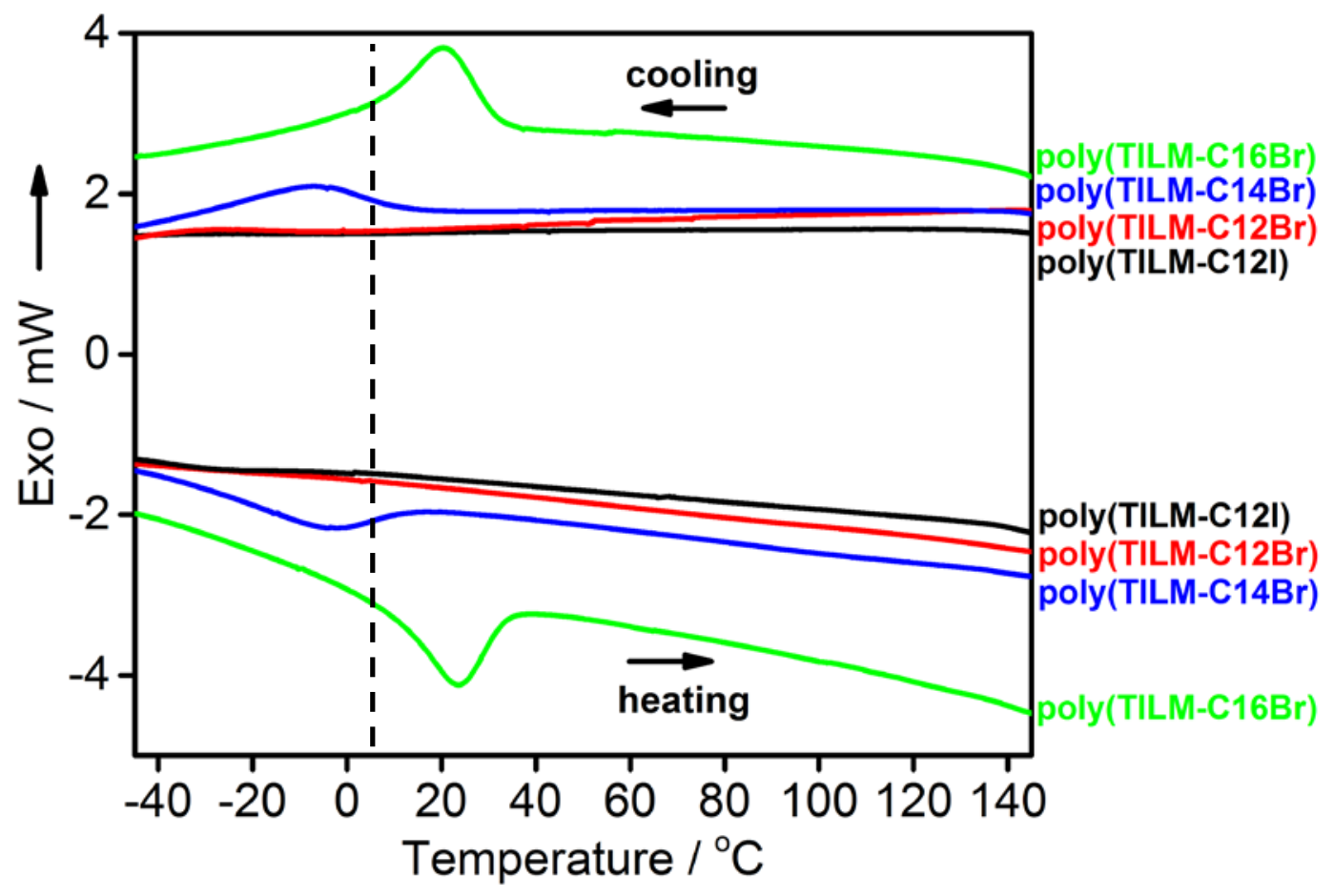

Figure S10. Differential scanning calorimetry curves of the dried solid poly(ionic liquid) polymers. The dash line indicates the preparation temperature of cryo-EM samples. Thermogravimetric analysis measurements showed that all poly(ionic liquid) samples started to decompose at ca. $250{ }^{\circ} \mathrm{C}$ under $\mathrm{N}_{2}$ and left a residue of $1.0 \pm 0.5 \mathrm{wt} \%$ at $1000{ }^{\circ} \mathrm{C}$. 

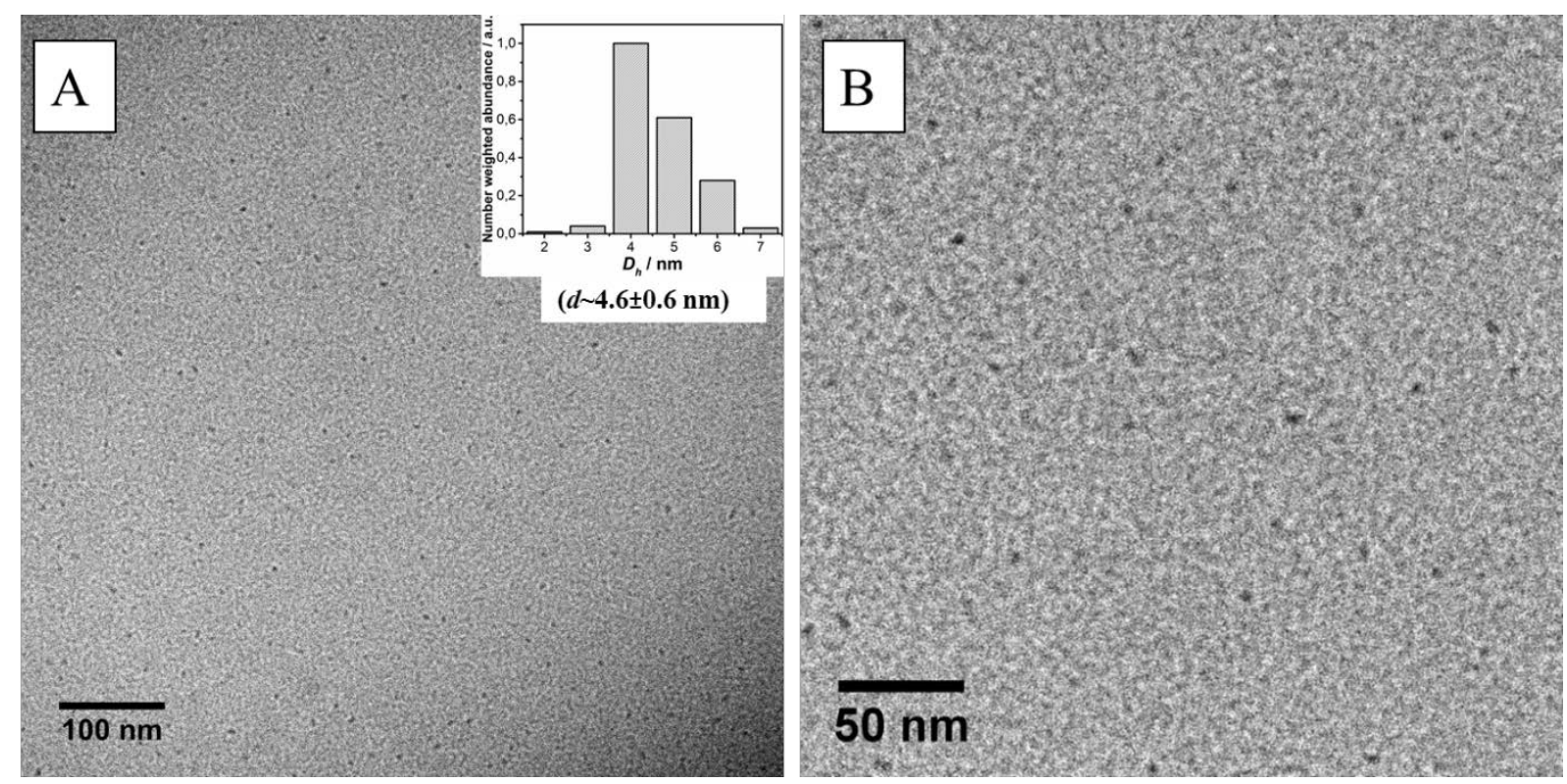

Figure S11. Cryo-EM image of aqueous solution of TILM-C14Br at c=30 g/L. (A) Overview. The insert is a size distribution curve derived from dynamic light scattering measurement of the same sample. (B) Close view of the cryo-EM image, only micelles (dark dots) can be found overall in the suspension solution. No multilamellar or unilamellar vesicles were identified. Their size was rather small, ca. $5 \mathrm{~nm}$ in diameter, as determined from the DLS measurements. This result revealed that the PIL nanoparticles did not form from the solutions of ionic liquid monomers before the polymerization, but during the polymerization. 

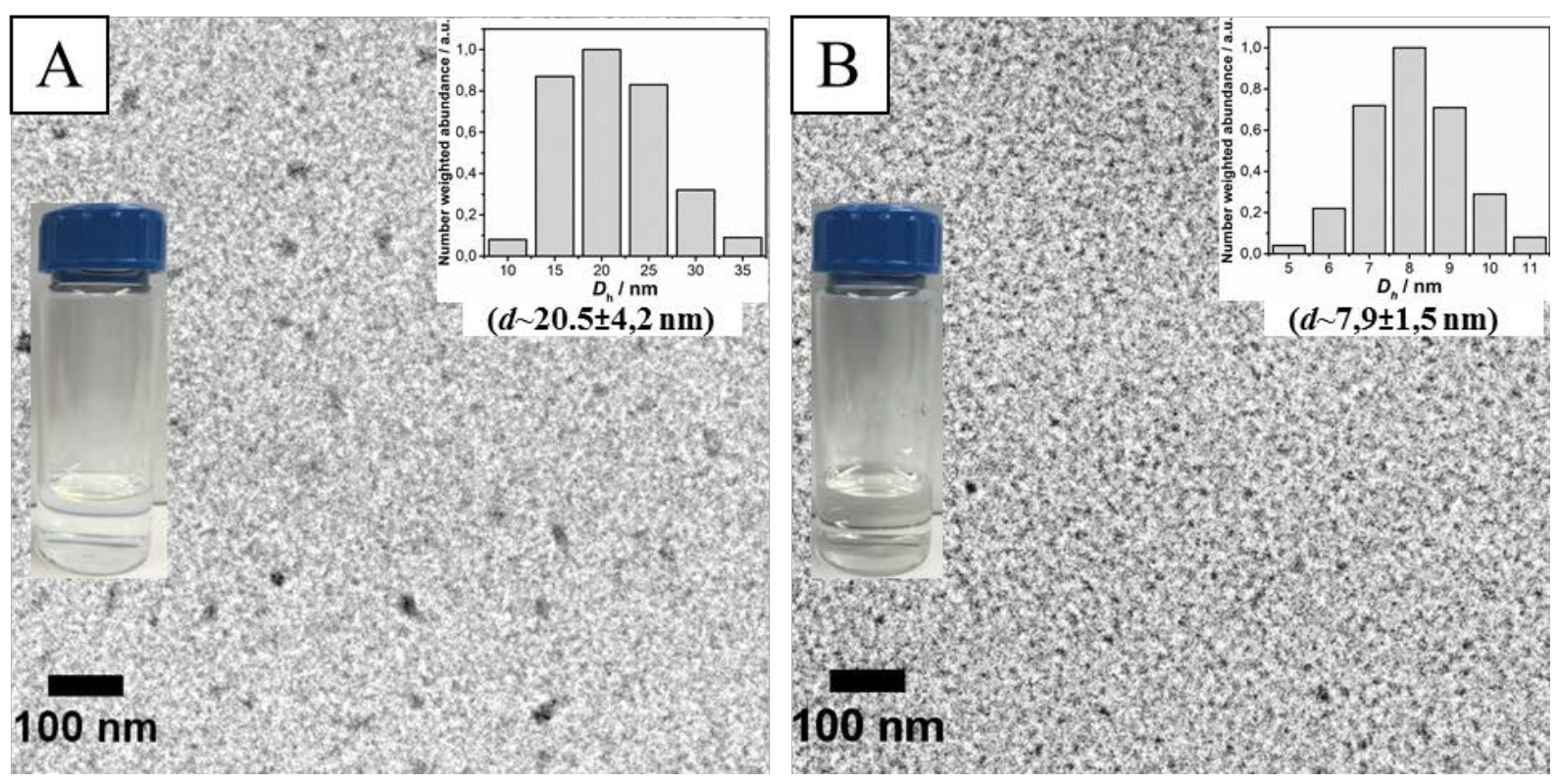

Figure S12. A) a TEM image of the poly(TILM-C12Br) (5 g/L) dispersion when produced via dispersion polymerization in water. B) a TEM image of a re-dispersed sample. To prepare this sample, the original PIL nanoparticle dispersion was freeze-dried to produce a white powder. This powder was dissolved in DMF. The DMF solution was then dialyzed in water to produce an aqueous dispersion of $5 \mathrm{~g} / \mathrm{L}$.
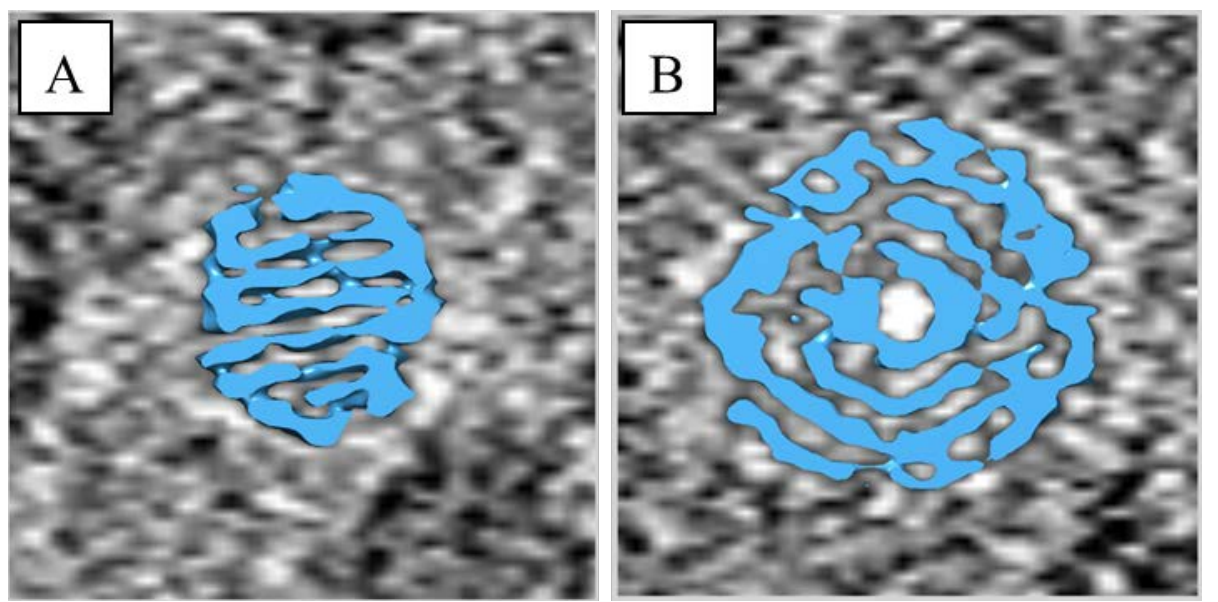

Figure S13. 3D renderings (before tilting) of (A) poly(TILM-C12Br) and (B) poly(TILMC16Br) PIL nanoparticles that have been clipped along the $\mathrm{Z}$ axis at their central regions. Tomographic slices along the $\mathrm{Z}$ axis of the tomographic volume at a slight offset with respect to the clipping planes are also shown. 

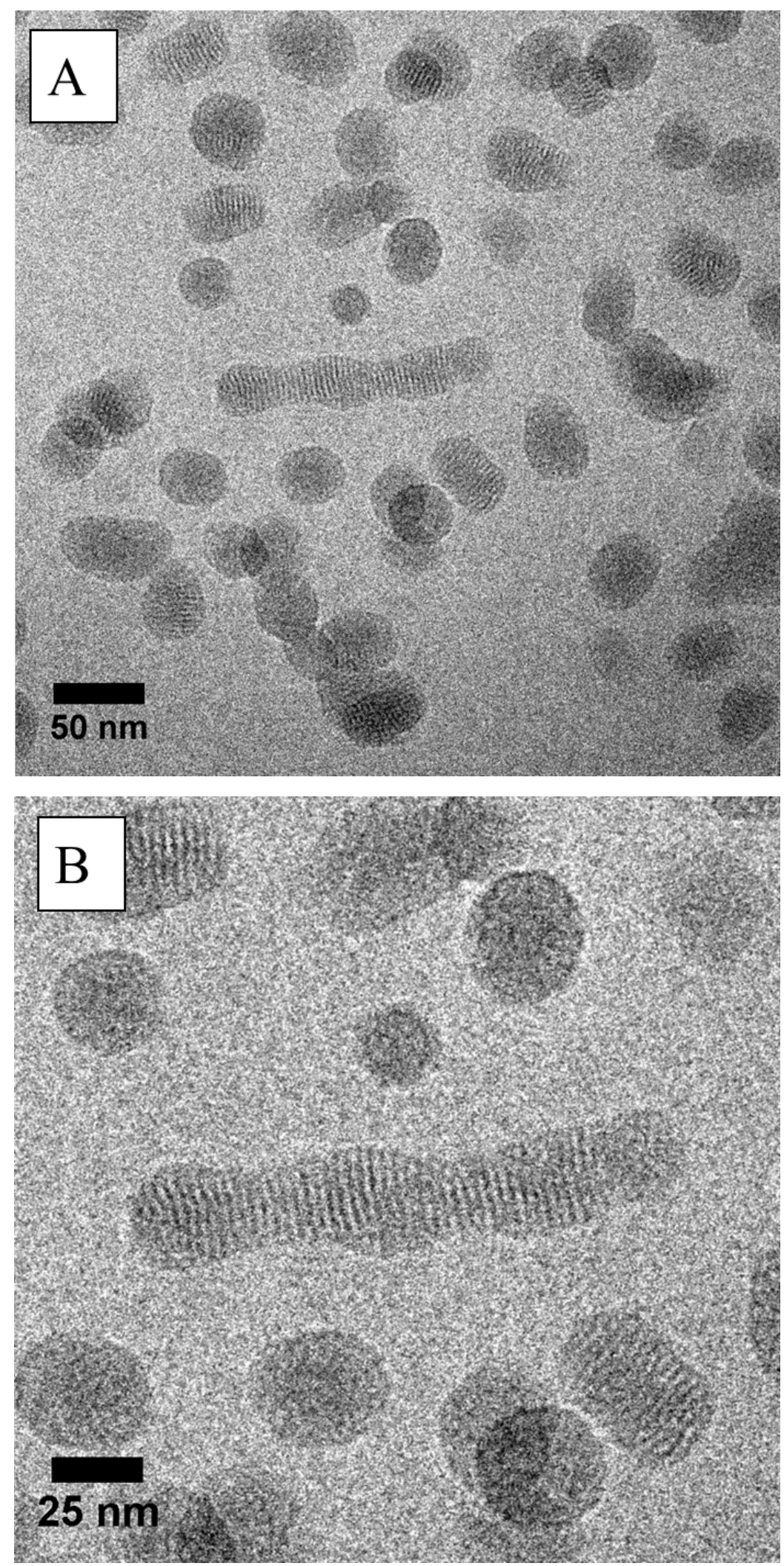

Figure S14. Cryo-EM images of elongated nanoworm superstructures of poly(TILM-C12I)

prepared with monomer concentration at $204 \mathrm{mM}$ (Entry 4, Table S2). (A) overview and (B) close view of the nanoworm. 

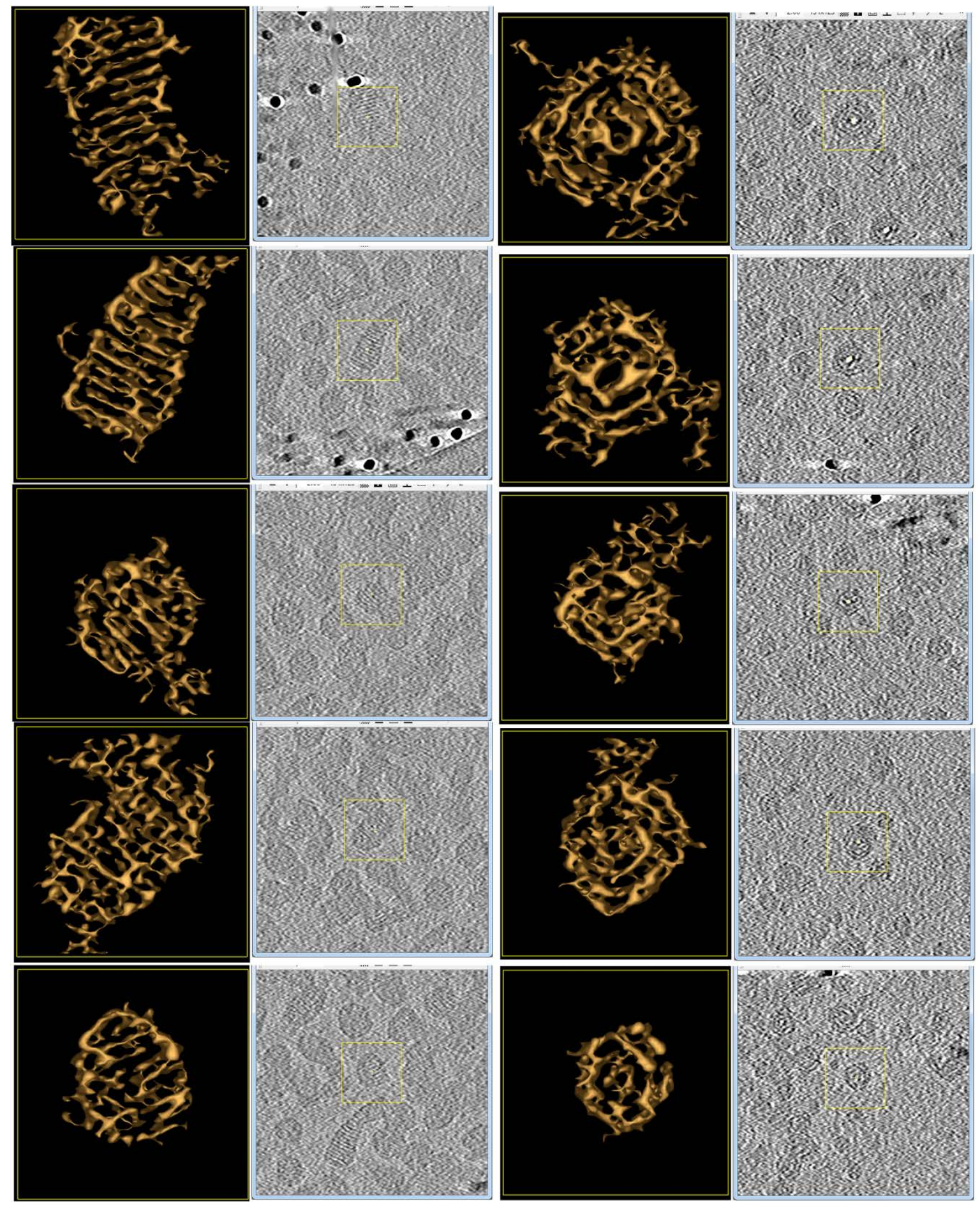

Figure S15. Representative cryo-ET images of PIL nanoparticles. Left: wasp models; right: onion models. 

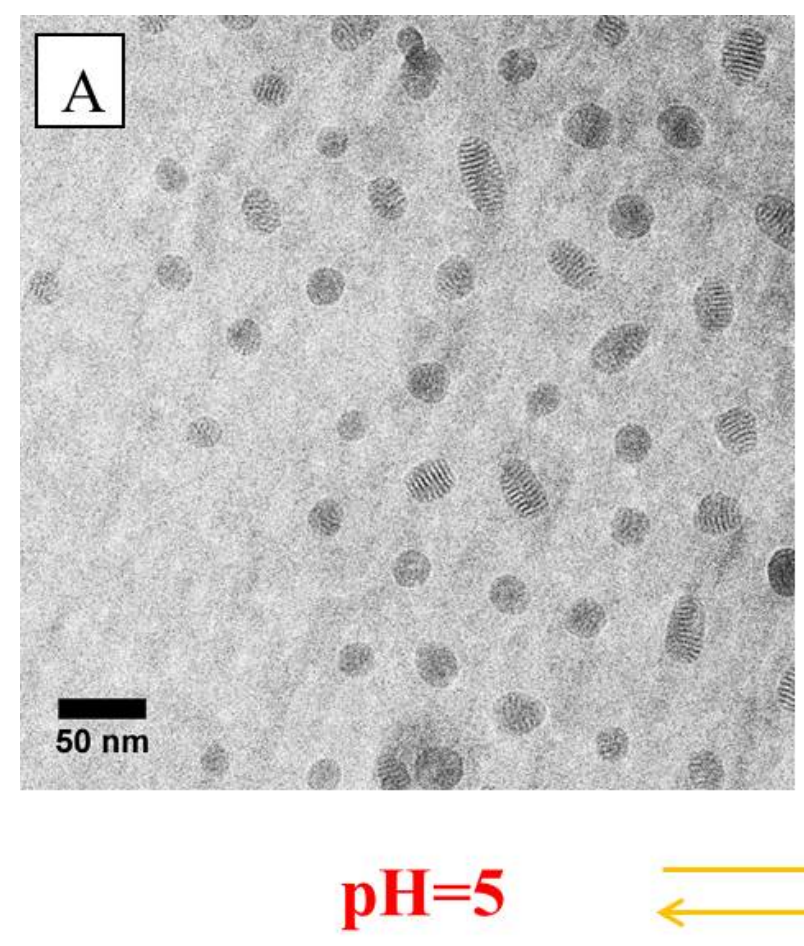
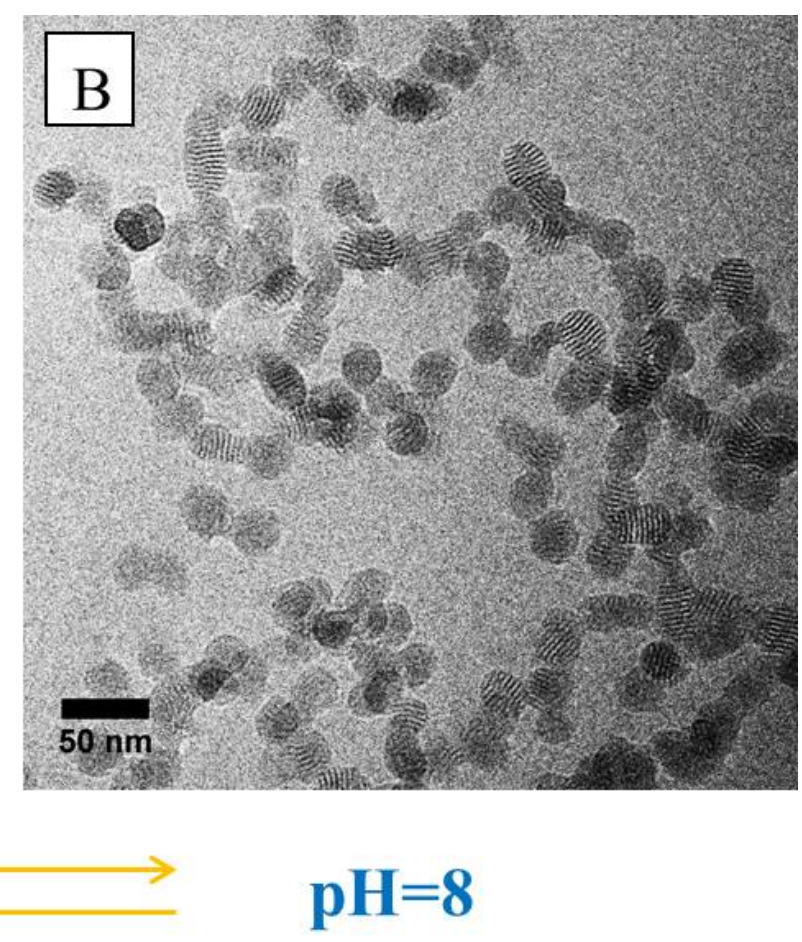

Figure S16. Overview of Cryo-EM images of $\mathrm{pH}$ responsive PIL nanoparticles in aqueous solution: (A) poly(TILM-C12Br) before adding ammonium hydroxide ( $\mathrm{pH}=5)$; (B) poly(TILM-C12Br) after adding ammonium hydroxide ( $\mathrm{pH}=8)$.

Table S1. The $d$ spacing values of poly(TILM-C12I), poly(TILM-C12Br), poly(TILM$\mathrm{C} 14 \mathrm{Br}$ ) and poly(TILM-C16Br) nanoparticles received from small-angle X-ray scattering (SAXS) measurements and cryo-EM images .

\begin{tabular}{c|c|c} 
Compound & $\begin{array}{c}\boldsymbol{d} \text { spacings }\left(\mathbf{d}_{\mathbf{2}}\right) \text { from SAXS } \\
\text { measurements } / \mathbf{~ n m}\end{array}$ & $\begin{array}{c}\boldsymbol{d} \text { spacings }\left(\mathbf{d}_{\mathbf{1}}\right) \text { from cryo-EM } \\
\text { images } / \mathbf{~ n m}\end{array}$ \\
Poly(TILM-C12I) & $2.15 \pm 0.4$ & $3.10 \pm 0.5$ \\
Poly(TILM-C12Br) & $2.22 \pm 0.7$ & $3.20 \pm 0.5$ \\
Poly(TILM-C14Br) & $2.56 \pm 1.1$ & $3.55 \pm 0.5$ \\
Poly(TILM-C16Br) & $2.99 \pm 1.9$ & $4.00 \pm 0.5$ \\
\hline
\end{tabular}


Table S2. Nanoparticle sizes obtained from different monomer concentrations in the dispersion polymerization of TILM-C12Br. The initiator concentration (6.50 mM) was kept constant during polymerization in water.

\begin{tabular}{c|c|c|c}
\hline Entry & $\begin{array}{c}\text { Monomer concentration } \\
\text { in } \mathbf{m} \boldsymbol{M}(\mathbf{i n} \mathbf{g} / \mathbf{L})\end{array}$ & $\begin{array}{c}\text { Polymerization } \\
\text { temperature }\left[{ }^{\circ} \mathbf{C}\right]\end{array}$ & $\boldsymbol{D}_{\boldsymbol{h}}[\mathbf{n m}]^{a)}$ \\
\hline 1 & $25.5(10 \mathrm{~g} / \mathrm{L})$ & 70 & 22 \\
2 & $51.1(20 \mathrm{~g} / \mathrm{L})$ & 70 & 21 \\
3 & $102(40 \mathrm{~g} / \mathrm{L})$ & 70 & 28 \\
4 & $204(80 \mathrm{~g} / \mathrm{L})$ & 70 & 75 \\
5 & $408(160 \mathrm{~g} / \mathrm{L})$ & 70 & 120 \\
6 & $51.1(20 \mathrm{~g} / \mathrm{L})$ & 60 & 23 \\
7 & $51.1(20 \mathrm{~g} / \mathrm{L})$ & 80 & 24 \\
8 & $51.1(20 \mathrm{~g} / \mathrm{L})$ & 90 & 26 \\
\hline
\end{tabular}

a) The hydrodynamic diameter $D_{h}$ was determined from DLS measurement. 